\title{
PHARMACOLOGICAL STUDIES OF NEOPICRORRHIZA SCROPHULARII- FLORA AND ITS ANTIDIABETIC EFFECT
}

\author{
Nayan Manandhar \\ Department of Pharmacy, Institute of Medicine, Maharajgunj Medical Campus, Maharajgunj, Nepal.
}

\begin{abstract}
Neopicrorrhiza srophulariiflora (NS), locally known as "kutki / katuki" in nepali is available in 3500$4800 \mathrm{~m}$ of Nepal. The present study was carried out to evaluate the antidiabetic property of NS in streptozotocin (STZ) induced type 2 diabetic model rats. NS dried rhizomes, was extracted with $80 \%$ ethanol and water by cold percolation method. The extracts were administered at a dose of $1.25 \mathrm{gkg}^{-1}$ body weight for 21 consecutive days to type 2 diabetic male Long-Evans rats, bred at BIRDEM animal house. Serum glucose was estimated by GOD PAP method. Ethanol extract of $N$. srophulariiflora significantly $(\mathrm{p}<0.05)$ improved oral glucose tolerance in type 2 rats in comparison to control group. The water extract and ethanol extracts significantly lowered serum glucose level of type 2 diabetic rats in both prandial states (simultaneously with oral glucose load $\mathrm{p}<0.05$; at $75 \mathrm{~min}$ and 30 minutes prior to oral glucose load $\mathrm{p}<0.05$; at $105 \mathrm{~min}$ ) compared to control group. $N$. srophulariiflora is beneficial for treating Type 2 diabetes and therefore needs further exploration and researches, both chemically and biologically to identify the active principle(s) and mechanism of action.
\end{abstract}

Key words: Anti-hyperglycemic, hypoglycemic, Neopicrorrhiza srophulariiflora.

Correspondence author

Nayan Manandhar

nayan.manandhar@yahoo.com; nayanmanandhar@iom.edu.np 


\section{INTRODUCTION}

Diabetes mellitus is a group of metabolic diseases characterized by hyperglycemia resulting from defects in insulin secretion, insulin action or both. It is the most common endocrine disorder affecting mankind all over the world, prevalence of which is increasing day by day. ${ }^{1}$ Type 2 Diabetes Mellitus is more prevalent and account for about $90 \%$ to $95 \%$ of all diagnosed cases of diabetes. By 2030, it is estimated that the number of people with diabetes $>64$ years of age will be $>82$ million in developing countries and $>48$ million in developed countries. ${ }^{2}$ In case of Nepal, a study found $9.1 \%$ in urban areas and $1.3 \%$ in rural areas. ${ }^{3}$

Considering the limitations of existing therapies in restoring the quality of life to normal as well as reducing the risk of chronic diabetic complications, search for alternating sources is a requirement. ${ }^{4}$

Neopicrorrhiza srophulariiflora (Family: Scrophulariaceae), is a prostrate herb with perennial woody rhizomes covered with old leaves at the base. ${ }^{5}$ It constitutes kutkin, a bitter glycosidal principle, D-mannitol, vanillic acid and some steroids are reported. Kutkin contains C-9 iridoid glycosides-Picroside I and Kutakosid, Apocynin. Picroside II has been isolated and shown to have hepatoprotective activity. ${ }^{6}$ It promotes secretion of bile, improves appetite and stimulates gastric secretion. ${ }^{6}$ In traditional medicine it has been used to treat liver, dropsy, antiperiodic fever, anemia jaundice and bronchial problems. ${ }^{7}$
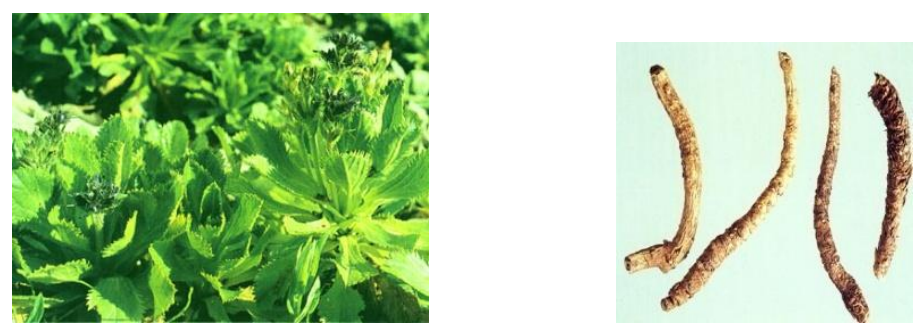

Fig. 1: Neopicrorrhiza srophulariflora plant and rhizomes

\section{METHODS}

Preparation of the extract: The powdered N. srophulariiflora rhizomes (2000gms) were extracted with $80 \%$ ethanol by cold percolation method. Similarly, the water extract was also prepared using the same method.

Animal models: Adult male Long-Evans rats, weighing (180-250) gms were used throughout the study, maintained at ambient room temperature.

Preparation of Type 2 diabetes (NIDDM) Model rats: Type 2 diabetes was induced by intraperitoneal injection of streptozotocin (STZ) at a dose of $90 \mathrm{mg} / \mathrm{kg}$ body weight $/ 10 \mathrm{ml}, \mathrm{pH} 4.5$ citrate buffer $(0.1 \mathrm{M}))$ to the 48 hours old rat pups as described by Bonner et.al. $^{8}$ 


\section{Chronic experiment}

The chronic experiment was carried out for duration of 21days on a total of 16 rats. These rats were divided into 3 groups, they are as follows:

- Normal Water Control group ( $\mathrm{n}=4)$ : This group was fed with deionized water (dose $10 \mathrm{ml} / \mathrm{kg}$ bw).

- NIDDM Glibenclamide positive control group ( $\mathrm{n}=4)$ : This group was fed with glibenclamide (dose of $5 \mathrm{mg} / \mathrm{kg} \mathrm{bw}^{1}$.

- NIDDM Treated group ( $\mathrm{n}=10)$ : This group was fed with $80 \%$ ethanolic extract of Picrorrhiza ( dose of $1.25 \mathrm{~g} / \mathrm{kg} \mathrm{bw})^{9}$

After the treatment, they were finally sacrificed on the $21^{\text {st }}$ day and the antihyperglycemic/ hypoglycemic properties were deduced from the blood glucose level on the $0^{\text {th }}$ and $21^{\text {st }}$ day's.

\section{Acute Experiment}

The acute effects of the on hypoglycemic activity of $80 \%$ Ethanol and water extract of Neopicrorrhiza Scrophulariiflora rhizomes, were observed in two different prandial states as described below-

Acute effect on serum glucose level when fed simultaneously with glucose: The extracts $(1.25$ $\mathrm{g} / \mathrm{kg} \mathrm{bw})$ were fed with glucose $(2.5 \mathrm{~g} / 10 \mathrm{ml} / \mathrm{kg} \mathrm{bw})$ to overnight fasted rats at 0 minute and blood samples were drawn at $0,30,75$ minutes. Both positive control and water control rats were fed with glucose solution at a dose of $2.5 \mathrm{~g} / 10 \mathrm{ml} / \mathrm{kg}$ bw. ${ }^{9}$

Acute effect on serum glucose level when fed $\mathbf{3 0}$ minute before glucose load: The extracts $(1.25$ $\mathrm{g} / \mathrm{kg} \mathrm{bw})$ were fed to overnight fasting $(12 \mathrm{hrs})$ rats at 0 minute and glucose load $(2.5 \mathrm{~g} / 10 \mathrm{ml} / \mathrm{kg}$ bw) were given at 30 minutes. Blood samples were drawn at $0,60,105$ minutes. The control group received water $(10 \mathrm{ml} / \mathrm{kg} \mathrm{bw})$ following glucose load of $2.5 \mathrm{~g} / 10 \mathrm{ml} / \mathrm{kg} \mathrm{bw} .{ }^{9}$

Biochemical Procedures: Serum glucose was estimated on the same day by GOD-PAP method. ${ }^{11}$

Data and Statistical Analysis: Data were analyzed using the SPSS version 12. All the data were expressed as Mean \pm standard deviation. Statistical analysis of the results had been analyzed by using the student's t-test (paired and unpaired), ANOVA (analysis of variance) to ensure an overall error rate of $5 \%$. Differences were considered significant at $\mathrm{p}<0.05$.

\section{RESULTS}

It is seen from the Table 1 that the changes of the body weight of rats were not remarkable between different treated groups during treatment period. 
Table 1: Chronic effect of N. scrophulariflora rhizome extract on body weight (gm) of Type 2 diabetic model rats

\begin{tabular}{lllll}
\hline Treatment & \multicolumn{4}{c}{ Experimental period (day) } \\
& BW_0 (gm) & BW_7 $(\mathbf{g m})$ & BW_14 (gm) & BW_21(gm) \\
\hline WC $(\mathbf{n}=\mathbf{6})$ & $218 \pm 25$ & $218 \pm 24$ & $221 \pm 17$ & $220 \pm 12$ \\
Gliben $(\mathbf{n}=\mathbf{6})$ & $223 \pm 17$ & $218 \pm 14$ & $219 \pm 14$ & $211 \pm 80$ \\
Picrro_et $(\boldsymbol{n}=\mathbf{8})$ & $221 \pm 33$ & $208 \pm 22$ & $214 \pm 19$ & $216 \pm 18$ \\
\hline
\end{tabular}

Data are presented as Mean $\pm \mathrm{SD} \mathrm{WC}=$ Water control, Gliben $=$ Glibenclamide, Picrro_et $=$ Picrrorhiza ethanol extract. Compared using paired ' $\mathrm{t}$ ' test. Between group comparison was done using one way ANOVA $* \mathrm{p}<0.01, * * \mathrm{p}<0.001$. $\mathrm{n}=$ number of rats

Regarding the acute effects when fed simultaneously with glucose load, the control drug glibenclamide showed significant hypoglycemic effects at $75 \mathrm{~min}$. Similarly, the $P$. scrophulariflora rhizome ethanol and water extracts also showed significant glucose lowering effect $(\mathrm{p}<0.01-0.05)$ at $30 \mathrm{~min}$ and $75 \mathrm{~min}$.

Table 2: Acute effects of $N$. scrophulariflora rhizome ethanol and water extracts on serum glucose level of type 2 diabetic model rats when fed simultaneously with glucose load

\begin{tabular}{lccc}
\hline Group & Glu_0 Min $(\mathbf{m M o l} / \mathbf{l})$ & Glu_30Min $(\mathbf{m M o l} / \mathbf{l})$ & Glu_75 Min $(\mathbf{m M o l} / \mathbf{l})$ \\
\hline WC $(\mathrm{n}=6)$ & $7.31 \pm 0.60$ & $17.04 \pm 4.80$ & $17.61 \pm 4.08$ \\
Gliben $(\mathrm{n}=6)$ & $7.95 \pm 1.14$ & $17.86 \pm 3.50$ & $13.98 \pm 4.67^{*}$ \\
Picrro_et $(n=8)$ & $7.80 \pm 0.85$ & $15.92 \pm 2.60^{*}$ & $14.40 \pm 4.16^{*}$ \\
Picrro_wt $(n=6)$ & $8.11 \pm 1.26$ & $13.85 \pm 2.33^{*}$ & $12.58 \pm 3.01^{*}$ \\
\hline
\end{tabular}

Data are presented as Mean $\pm \mathrm{SD} \mathrm{WC}=$ Water control, Gliben= Glibenclamide, Picrro_et= Picrrorhiza ethanol extract Picrro_wt = Picrrorhiza water extract ANOVA (Bonferroni test) was done as the test of significance. ${ }^{*} \mathrm{p}<0.01-0.05$

Table 3: Acute effect of Picrrorhiza scrophulariflora rhizome extract on serum glucose levels of type 2 rats when the extract was fed 30 minutes before to glucose load.

\begin{tabular}{lccc}
\hline Group & Glu_o Min $(\mathbf{m M o l} / \mathbf{l})$ & Glu_60 Min $(\mathbf{m M o l} / \mathbf{l})$ & Glu_105 Min (mMol/l) \\
\hline WC $(\mathrm{n}=6)$ & $8.44 \pm 0.88$ & $17.65 \pm 6.03$ & $20.22 \pm 5.45$ \\
Gliben $(\mathrm{n}=6)$ & $7.41 \pm 1.18$ & $14.73 \pm 7.61^{*}$ & $14.28 \pm 5.20^{*}$ \\
Picrro_et $(n=8)$ & $7.21 \pm 0.98$ & $16.90 \pm 6.00$ & $14.50 \pm 5.12^{*}$ \\
\hline
\end{tabular}

Data are presented as Mean $\pm \mathrm{SD} \mathrm{WC}=$ Water control, Gliben $=$ Glibenclamide, Picrro_et $=$ Picrrorhiza ethanol extract ANOVA (Bonferroni test) was done as the test of significance. ${ }^{*} \mathrm{p}<0.01$ 0.05 . 
When the extract was fed 30 minutes before the glucose load, the plant has significant glucose lowering effect (Table 3). Glibenclamide as a standard drug significantly lowered serum glucose levels at both time points i.e. at 60 minutes and at 105 minutes $(\mathrm{p}<0.01-0.05)$. And the $80 \%$ ethanol extract of $P$. scrophulariflora also lowered at $105 \min (\mathrm{p}<0.01-0.05)$.

Table 4 illustrates the level of blood glucose in the control and experimental group of rats on 0 day and $21^{\text {st }}$ day. As it is seen at baseline the mean $( \pm \mathrm{SD})$, ethanol extract of $N$. scrophulariflora showed a significant decrease while comparing within groups $(\mathrm{p}<0.01)$. As expected, glibenclamide also ameliorated the diabetic condition on $21^{\text {st }}$ day.

Table 4: Chronic effect of $N$. scrophulariflora rhizome extract on fasting glucose level of type 2 diabetic model rats

\begin{tabular}{llc}
\hline Groups & \multicolumn{2}{c}{ Mean \pm SD } \\
\cline { 2 - 3 } & Glu_0 day $(\mathbf{m M o l} / \mathbf{l})$ & Glu_21 \\
\hline WC $(\mathrm{n}=6)$ & $7.20 \pm 0.66$ & $6.58 \pm 1.50$ \\
Gliben $(\mathrm{n}=6)$ & $7.44 \pm 1.17$ & $5.86 \pm 1.05$ \\
Picrro_et $(n=8)$ & $7.89 \pm 0.86$ & $5.95 \pm 0.79^{*}$ \\
\hline
\end{tabular}

Data are presented as Mean $\pm \mathrm{SD} \mathrm{WC}=$ Water control, Gliben= Glibenclamide, Picrro_et= Picrrorhiza ethanol extract. Compared using paired ' $t$ ' test. Between group comparison was done using one way ANOVA with post Hoc Bonferroni test. ${ }^{*} \mathrm{p}<0.01$. $\mathrm{n}=$ number of rats

\section{DISCUSSION}

Type 2 diabetes was induced using streptozotocin to neonates rats described by Boiner et al. to evaluate the activity of antidiabetic agents. ${ }^{12}$ These results demonstrates, that both ethanolic extract $(80 \%)$ and water extract of $N$. srophulariflora in type 2 diabetic rats showed significant hypoglycemic effect $(\mathrm{p}<0.01-0.05)$ in type 2 model rats, when the extracts were fed simultaneously with oral glucose load. Hypoglycemic activity that is found when given with a simultaneous glucose load in diabetic rats indicates that the extracts may interfere with the intestinal glucose absorption in the gut by various mechanisms. ${ }^{13}$

The extracts showed significant hypoglycemic effect in both prandial states (simultaneously with oral glucose load p<0.01-0.05; at 75min and 30 minutes, and prior to oral glucose load $\mathrm{p}<0.01-0.05$; at 105min duration) (Table 2 and 3). It indicates that the plant rhizomes might contain some hypoglycemic principle(s) which probably act by initiating the release of insulin from pancreatic $\beta$ cells. ${ }^{14}$ The hypoglycemic activity of the extract after 21 days of consecutive feeding, can postulate that the extract may act by reducing glycogenolysis in liver which reflects in reducing the blood glucose level. ${ }^{15}$ Post pandrial reduction in glucose level by the $N$. srophulariiflora suggests that it may also interfere with intestinal glucose absorption or stimulation of glycogenesis (enhanced by feeding) and improving the insulin-secretory capacity or enhancement of insulin action by the extract. 


\section{CONCLUSION}

Thus the accumulating evidences suggests that both pancreatic and extra pancreatic mechanisms might be involved in $N$. srophulariiflora anti-diabetic or antihyperglycemic action, which can be beneficial for the treatment of diabetes.

\section{REFERENCES}

1. Pickup JC, Williams G. Chapter 2: The diagnosis and classification of diabetes and impaired glucose regulation; Text book of Diabetes: Selected chapters ( $3^{\text {rd }}$ Edition); 2005: 2.1-2.13.

2. Wild S, Roglic G, Green A, Sicree R, King H (May 2004). "Global prevalence of diabetes: estimates for the year 2000 and projections for 2030". Diabetes Care 27 (5): 1047-53. Doi:10.2337/diacare.27.5.1047.

3. S. Haruka, K. Terukaju, O. Tetsuro, K. Sigeru, I. Kazue, Y. Yutaka, S. Sashi, A.Gopal. The Prevalence of diabetes mellitus and impaired fasting glucose/ glycaemia (IFG) in suburban and rural Nepal - the community based cross sectional study during the democratic movements in 1990. Vol 67, Issue 2, pg 167-174.

4. Williamson EM, Okpako DT, and Evans FJ. (1996). Pharmacological Methods in Phytotherapy Research. Vol.I with type 1 diabetes. N Engl J Med; 353, 2643-2653. PMID 16371630.

5. Suwal, P.N. (2007) Medicinal plants of Nepal. Revised., Government of Nepal, Ministry of Forests and Soil Conservation, Department of Plant Resources, Kathmandu, p. 63.

6. What is Picrorrhiza Root and it's major application?

7. Friso Smit. Picrorhiza scrophulariiflora from traditional use to immunomodulatory activity

8. Bonner-Weir, S.; Trent, D.F.; Honey, R.N. and Weir, G.C. (1981). Responses of neonatal rat islets on srteptozotocin limited beta cell regeneration and hyperglycemia. Diabetes: 30, 64-69

9. Ali L, Khan AKA, Mamun MIR, Mosihuzzaman M, Nahar N, Nur-e-Alam M Rokeya B. Hypoglycemic effect of fruit pulp, seed and whole plant of Momordica charantia on normal and diabetic model rats. Plant Medica (1993) October 59: 408-412

10. Mamun MIR, Rokeya B, Choudhury NS, Muniruzzaman M, Nahar N, Ahmed MU, Mosihuzzaman M, Ali L, Khan AKA, Khan SH. Anti-hyperglycemic effect of Pterospermum acerifolium Wild and Pterospermum semisagittatum Ham. Diabetic Research (2001) 35: 163-170

11. Chu SY, Cheung P. Experience with Boehringer Mannheim GOD/PAP (Trinder) glucose reagent kit on Autoanalyser I and SMA 12/60 systems. Clinical Biochemistry, (1978) August 11(4): 187189.

12. Lvedoux, SP, Woodly SE, Patton NJ, Wilson $\operatorname{Lg}(1986)$. Mechanism of nitrosoura- induced $\beta$ cell damage alteration in DNA. Diabetes $35,866-872$

13. Joy, K.L., Kuttan, R.,(1999). Picrorrhiza kurroa extract. J. Ethnopharmacol. 67, 143-148.

14. Lee, H.S., Ahn, H.C. and Ku, S.K. (2006a). Hypolipemic effect of water extracts of Picrorrhiza rhizome in PX- 407n induced hyperlipemic ICR mouse model with hepatoprotective effects: A preventive study. J. Ethnopharmacol. 105, 380-386.

15. Lee, H.s., Yoo, C.B. and Ku, S.K. (2006b). Hypolipemic effect of water extracts of Picrorrhiza rhizome in high fat diet treated mouse Fitoterapia. 2006; 77:579-584.

16. Nahar N, Rokeya B, Ali L, Hassan Z, Nur-e-Alam M, Choudhury NS, Khan AKA, Mosihuzzaman M. Effect of three medicinal plants on blood glucose levels in nondiabetic and diabetic model rats. Diabetic Research (2000) 35: 041-049. 